\title{
Hemorragia intracraneal por aneurismas y malformaciones arteriovenosas durante el embarazo y el puerperio
}

\author{
S.D. Vega-Basulto; E. Lafontaine-Terry; F.G. Gutiérrez-Muñoz; J. Roura-Carrasco y G. Pardo-Camacho
}

Servicio de Neurocirugía y de Terapia Intensiva. Hospital “Manuel Ascunce Doménech”. Departamento de Obstetricia. Hospital “Ana Betancourt de Mora". Camagüey. Cuba.

Resumen

Introducción. La hemorragia subaracnoidea por aneurismas y malformaciones arteriovenosas es más frecuente en gestantes y puérperas. Analizamos el comportamiento de estas pacientes, su manejo y el efecto sobre ellas de nuestro Programa Nacional Materno Infantil.

Pacientes y métodos. Hubo 437 gestantes y 717 puérperas complicadas en el periodo de enero de 1996 a diciembre del 2005, 41 muertes maternas por todas las causas y 14 defunciones maternas indirectas. Fueron intervenidos 454 pacientes con aneurismas intracraneales y malformaciones arteriovenosas intracraneales. El obstetra evaluó las pacientes complicadas y el feto, para decidir la forma del parto. Las pacientes fueron manejadas precozmente por un colectivo médico interdisciplinario. Las lesiones vasculares fueron clipadas por métodos microneuroquirúrgicos. El manejo anestésico consideró los problemas inherentes a la gestación y al feto. No utilizamos métodos endovasculares. El seguimiento postoperatorio fue en la sala de Terapia Intensiva.

Resultados. Hubo un total de ocho pacientes, entre gestantes y puérperas con hemorragia subaracnoidea por aneurismas o malformaciones arteriovenosas intracraneales. Seis tenían aneurismas intracraneales y dos malformaciones arteriovenosas. Realizamos siete intervenciones quirúrgicas, cinco en aneurismas y dos en malformaciones. Cuatro pacientes lograron una recuperación neurológica completa, dos una recuperación parcial y hubo dos fallecidas. Esta enfermedad constituyó el $14 \%$ de todas las causas de muertes maternas indirectas.

Conclusión. Un mejor diagnóstico clínico, los estudios por imágenes y el manejo interdisciplinario precoz que vincula la terapia intensiva, la atención obstétrica y los servicios de neurocirugía vascular determinan un incremento en el diagnóstico de estas lesiones que

Recibido: 28 -03-07. Aceptado: 30-05-07 requieren un tratamiento microneuroquirúrgico o endovascular rápido y oportuno para evitar la muerte materna y el grave daño del feto.

PALABRAS CLAVE: Embarazo. Puerperio. Hemorragia subaracnoidea. Aneurismas intracraneales. Malformaciones arteriovenosas.

\section{Summary}

Introduction. Subarachnoid hemorrhage for aneurysms and arteriovenous malformations is most frequent during pregnancy and puerperium. We analyzed behavior and management of this patients and the effect on it of our Maternal Health Program.

Patients and methods. There were 437 pregnancy and 717 puerperal complicated patients between january 1996 to december 2005, 41 maternal deaths of all causes and 14 indirect maternal deaths. There were operated on 454 patients with intracranial aneurysms and arteriovenous malformations in this period. Pregnant patients and fetus were evaluated to select mode of delivery. A specialized medical team managed precociously these patients. Vascular lesions were clipped by microsurgical methods. Anesthetic management considered pregnancy and fetal complexities. We did not use endovascular methods. Postoperative management was performed on intensive care unit.

Results. There were eight pregnant and puerperal patients with subarachnoid hemorrhage due to aneurysms and arteriovenous malformations. $2 \%$ of all patients were operated on by this cause. Six harboured intracranial aneurysms and two arteriovenous malformations. We performed seven surgical procedures, five for aneurysms and two for malformations. There was a delivery rate of 2.1 and seven normal newborn. Four patients achieved a complete neurological recovery, two a partial recovery and there were two deceaseds. This cause constituted $14 \%$ of all indirect maternal deaths.

Conclusion. A precocious clinical diagnosis, neuroimaging studies and interdisciplinary management 
that involve intensive therapy, obstetric attention and neurovascular surgical treatment determined an increment in the diagnosis of these lesions that require opportune microsurgical or endovascular treatment to prevent maternal death and fetal damage.

KEY WORDS: Pregnancy. Puerperium. Subarachnoid hemorrhage. Intracranial aneurisms. Arteriovenous malformations.

\section{Introducción}

Durante el embarazo y puerperio pueden desarrollarse numerosas enfermedades neurológicas y los trastornos neurológicos pregestacionales pueden influir en la aparición de una enfermedad en una paciente obstétrica no complicada ${ }^{1,9}$.

La hemorragia subaracnoidea ocurre con más frecuencia en pacientes gestantes, que en aquéllas no gestantes de la misma edad y la incidencia es de una por cada 10.000 embarazos, un promedio cinco veces mayor que en la mujer no grávida de la misma edad; sin embargo, existen muy pocas series donde se analicen este tipo de pacientes $^{3,4}$.

El manejo médico de la hemorragia intracraneal en la paciente grávida o puérpera difiere de la no gestante, porque debemos tener en cuenta la teratogenicidad de los medicamentos, su acción sobre el flujo sanguíneo uteroplacentario y el feto, los cambios gravídicos en la mujer, el riesgo de muerte materno-fetal, la elevada ansiedad familiar y los distintos programas nacionales de protección materno infantil que desencadenan un fuerte estado de tensión médica e institucional ${ }^{4,6,51}$.

La hemorragia intracraneal durante el embarazo y el puerperio origina un nutrido grupo de problemas a resolver, tales como: la realización del estudio imaginológico con protección radiológica, la viabilidad del feto, la forma del parto, el manejo neuroanestésico, las drogas a utilizar y la decisión de intervención neuroquirúrgica ${ }^{4,12,27}$.

El objetivo fundamental de este trabajo es analizar el comportamiento de las pacientes gestantes y puérperas con hemorragia subaracnoidea por malformación o aneurisma intracraneal en nuestra institución, reconocer el efecto de nuestro Programa Nacional Materno Infantil sobre ese grupo especial de pacientes y hacer diferentes señalamientos sobre su manejo, con vista a dar respuesta a todos los complejos problemas señalados.

\section{Pacientes y métodos}

Camagüey, es una provincia de la región central del país (Cuba) que tiene unos 800,000 habitantes. La expectativa de vida al nacer es de 77 años, el 15\% de la población es mayor de 60 años y la tasa de mortalidad infantil promedio del último decenio fue de 5.8. El Sistema de Salud en todo el país es totalmente gratuito, con fuerte apoyo estatal general y fácil acceso de toda la población a los servicios. El Programa Nacional de Atención Materno Infantil constituye una prioridad fundamental dentro del Sistema de Salud Cubano.

El promedio de partos por año en Camagüey en el último decenio fue de 9,646; el 100\% de los cuales fueron institucionales. Las gestantes son previamente captadas y atendidas por su médico de familia desde el primer trimestre del embarazo y reciben más de ocho controles médicos por el obstetra durante todo ese período.

En casos de complicación o riesgo, las pacientes son hospitalizadas con prontitud y evaluadas por las especialidades médicas que necesiten. Las gestantes o puérperas con complicaciones graves, que ponen en peligro la vida de la madre y del niño, son ingresadas en Unidades de Terapia Intensiva y evaluadas allí por los especialistas. La organización regional en todo el país permite que esa Unidad de Terapia Intensiva disponga de los recursos y equipamientos suficientes para dar respuestas a los problemas más complejos.

La sala de terapia intensiva del Hospital "Manuel Ascunce Domenech" de Camagüey (Cuba), desde su fundación hace más de treinta años, tiene la responsabilidad de atender a todas las gestantes y puérperas con complicaciones graves y el Servicio de Neurocirugía de esa misma institución evalúa todas las complicaciones neuroquirúrgicas.

En el período de enero de 1996 a diciembre del 2005 ingresaron 437 gestantes y 717 puérperas complicadas en la sala de terapia intensiva del Hospital "Manuel Ascunce Domenech". Hubo un total de 41 muertes maternas por todas las causas en este período. La tasa promedio fue de 3 defunciones por 10.000 partos por año, ligeramente menor a la nacional, que fue de 3.8. Las defunciones maternas por causa indirecta, no relacionada con el embarazo y el parto, fueron 14 .

En el periodo 1996-2005 fueron intervenidos un total de 454 pacientes con aneurismas intracraneales y malformaciones arteriovenosas intracraneales en nuestro servicio y seleccionamos las gestantes o puérperas con hemorragias subaracnoideas por aneurismas o malformaciones arteriovenosas, confirmadas en estudios neurorradiológicos y en intervenciones quirúrgicas. En el estudio por imágenes de las pacientes con hemorragia subaracnoidea obstétricas se siguió el mismo flujograma que en las no obstétricas: tomografía computarizada, angiotomografía cerebral y estudio angiográfico cerebral completo para confirmar la presencia de una malformación vascular. Fueron necesarios cuidados especiales para la protección del feto durante los procedimientos.

El estado clínico de las pacientes fue evaluado con la 
Tabla 1

Vías del parto en gestantes y puérperas con hemorragia intracraneal

\section{Complicación neurológica}

Ruptura de aneurisma

Malformación arteriovenosa rota

\section{Modo del parto}

Roto y no clipado en pacientes del tercer trimestre: cesárea

Roto y no clipado en pacientes del primer y segundo trimestre: parto vaginal

Si se reseca antes de las 35 semanas: parto vaginal

Si no se reseca, parto por cesárea
Escala de la Federación Mundial de Neurocirujanos ${ }^{7}$. En todas las pacientes en grado III y IV menos en una, se logró mejorar su estado clínico al ingreso, lo suficiente, para llevarlas al quirófano en un grado I ó II.

El obstetra realizó una evaluación clínica diaria de las pacientes y del feto, de su riesgo obstétrico y para decidir la forma del parto, aplicaron el flujograma de Wiebers ${ }^{52}$. (Tabla 1). Todas las pacientes fueron manejadas por un colectivo médico integrado por el intensivista, el obstetra, el neurólogo, el neurorradiólogo y el neurocirujano. Las decisiones terapéuticas siempre fueron acordadas por el colectivo y el equipo fue dirigido por el médico intensivista.

El tamaño de los aneurismas encontrados se evaluó según la clasificación propuesta por los Estudios Cooperativos de aneurismas de 1990, que considera como pequeños lo menores de $12 \mathrm{~mm}$, grandes los que miden entre 13 y 25 mm y gigantes los mayores de $25 \mathrm{~mm}^{19,20}$. Las malformaciones arteriovenosas fueron evaluadas utilizando la Escala de Spetzler y Martin ${ }^{42}$ que tiene en cuenta tres variables: el tamaño de la lesión, su elocuencia y si existió drenaje venoso profundo.

Nuestra institución desarrolla hace varios años un programa de notable interés por el tratamiento de las malformaciones vasculares intracraneales, por lo que dispone de personal especializado en la neuroanestesia vascular. El manejo anestésico tuvo en cuenta los siguientes aspectos: proporcionar un cerebro relajado que permitiera la disección y clipaje de las lesiones, no perjudicar a la gestante o puérpera y evitar el daño adicional del feto, en especial, por la hipotensión e hipoxia.

Realizamos tratamiento microneuroquirúrgico lo más rápido posible a partir del ingreso y en cuanto todas las condiciones relacionadas con la madre y el niño fueran óptimas. Todas las pacientes fueron llevadas al quirófano en la primera semana de la hemorragia y a través de un abordaje pterional, fueron clipadas las lesiones aneurismáticas. La cirugía de las malformaciones arteriovenosas se realizó acorde a las características de cada paciente. El seguimiento postoperatorio se realizó en la sala de terapia intensiva. Nuestra institución no utilizó métodos endovasculares. El resultado clínico final se valoró siguiendo la escala de pronósticos de Glasgow, que considera cinco estados: recuperación completa, recuperación parcial, incapacidad grave, estado vegetativo y fallecido ${ }^{18}$. Las decisiones médicas, en relación con la madre y feto, se consultaron y se aprobaron en una o varias entrevistas con los familiares ${ }^{49}$.

\section{Resultados}

En el periodo, hubo un total de ocho pacientes gestantes y puérperas con hemorragias subaracnoideas por aneurismas o malformaciones arteriovenosas intracraneales, cuyas características clínicas generales fueron resumidas en la Tabla 2. Estas hemorragias constituyeron menos del $2 \%$ del total de pacientes intervenidos por esas dos causas en los últimos diez años en la provincia. Hubo dos fallecidas dentro del grupo de embarazadas y puérperas. Seis pacientes tenían aneurismas intracraneales y dos malformaciones arteriovenosas. Predominaron las pacientes en la tercera y cuarta década de la vida y en el tercer trimestre del embarazo. El promedio de edad en las malformaciones arteriovenosas fue inferior al de las pacientes con aneurismas intracraneales.

En siete pacientes el sangrado ocurrió durante el embarazo y en una durante el puerperio. Una paciente con aneurisma intracraneal y embarazo en el primer trimestre ingresó en estadio IV, resangró al día siguiente y falleció sin ser intervenida. La causa del sangrado se comprobó en la autopsia. Las seis pacientes con aneurismas intracraneales tenían lesiones únicas y menores de 12 milímetros (pequeñas). No hubo aneurismas grandes ni gigantes en esta serie. Las lesiones aneurismáticas estaban ubicadas en el sistema carotídeo y no hubo lesiones en el territorio vertebrobasilar.

Realizamos siete intervenciones quirúrgicas, cinco en aneurismas y dos en malformaciones arteriovenosas. Las localizaciones de las lesiones aneurismáticas fueron: dos en la región de la comunicante posterior, dos en la cerebral media y una en la región de la comunicante anterior.

Dos pacientes tenían malformaciones arteriovenosas supratentoriales. Ambas eran lesiones grado II de la Escala 
Tabla 2.

Características clínicas de las pacientes

\section{Edad}

$\begin{array}{lc}16-25 \text { años } & 2 \\ 26-35 \text { años } & 6 \\ \text { io de edad en aneurismas } & 29.4 \\ \text { io de edad en malformaciones } & 26.7\end{array}$

Estado clínico

Grado 1

Grado 2

Grado 3

Grado 4

\section{Etiología}

Aneurismas intracraneales

Malformación arteriovenosa
Supratentoriales: 6

Infratentoriales: 0

2

\section{Trimestre de embarazo}

$\begin{array}{ll}\text { Primero } & 1 \\ \text { Segundo } & - \\ \text { Tercero } & 6\end{array}$
7

Operados

Fallecidos (2)

Resangrado antes de la operación 1

Vasoespasmo postoperatorio
6 de Spetzler y Martin: menores de tres centímetros, elocuentes; pero sin drenaje al sistema venoso profundo. Una de las lesiones era de localización frontal y otra silviana anterior. Ambas fueron resecadas totalmente por métodos microneuroquirúrgicos.

Hubo dos fallecidas en la serie, una antes de la intervención por resangrado y otra por vasoespasmo generalizado postoperatorio. La primera ingresó en un estadio IV y resangró al día siguiente del ingreso. La segunda tenía buen estado clínico, pero en la tomografía realizada y en el acto quirúrgico encontramos abundante sangre subaracnoidea; desarrolló un vasoespasmo postoperatorio generalizado que determinó la muerte.

Todas las pacientes habían tenido gestaciones y partos previos, con excepción, de una paciente nulípara con malformación arteriovenosa. El promedio general fue de 2.1 partos por gestante. Hubo siete recién nacidos de peso normal.

Las cinco gestantes con aneurismas intracraneales y embarazo en el tercer trimestre tuvieron parto por cesárea. Una de las fallecidas tenía un embarazo en el primer trimes- tre. Una de las puérperas con hemorragia subaracnoidea tuvo un parto normal y la otra cesárea iterada.

Cuatro pacientes lograron una recuperación neurológica completa y dos una recuperación parcial. No hubo pacientes con incapacidad grave.

Este tipo de enfermedad cerebrovascular hemorrágica constituyó el 14\% de todas las causas de muertes maternas indirectas del período y la tercera en frecuencia de ese grupo, precedida por las enfermedades cardiovasculares y el asma bronquial complicada.

\section{Discusión}

La hemorragia intracraneal durante el embarazo y el puerperio es una grave, pero relativamente infrecuente, complicación durante este periodo. La mejoría notable del manejo obstétrico ha reducido las muertes por causas directas en muchos países con sistemas de salud desarrollados y ha incrementado la importancia relativa de las hemorragias intracraneales como causa de morbilidad y mortalidad materna $^{11,13,21}$. Esta causa constituye del 5 al $80 \%$ de todas 
las defunciones indirectas en muchos centros ${ }^{35,38}$ y es una causa principal de muerte materna no obstétrica en nuestra provincia, donde representó el 14\% de estas muertes.

Por otra parte, el desarrollo de los estudios imaginológicos y la aplicación consciente de la protección radiológica durante la gestación han ayudado a confirmar las hemorragias por aneurismas y malformaciones arteriovenosas y han permitido diferenciarlas de las hemorragias por toxemias y otros procesos $\mathrm{s}^{3-5,43}$.

Un problema principal en muchos de los centros obstétricos no asociados a servicios neuroquirúrgicos está en la falta de reconocimiento temprano de esta causa de hemorragia, un elemento muy importante en la evolución de este tipo de enfermedades. Si bien la eclampsia, los trastornos de la coagulación ${ }^{5}$ y las neoplasias intracraneales primarias o metastásicas pueden confundir en muchas gestantes y puérperas, la elevada sospecha clínica y el diagnóstico temprano por imágenes son elementos trascendentales en casos de aneurismas y malformaciones arteriovenosas ${ }^{6,27}$.

En muchos estudios, la hemorragia subaracnoidea durante el embarazo y el puerperio por malformaciones vasculares constituyeron del 0.35 al $1.4 \%$ de todas las hemorragias subaracnoideas ${ }^{4,43,51}$, pero en nuestro territorio representaron el 2\% del total. Esas variaciones de frecuencia están relacionadas tanto con el reducido tamaño de muchas de esas series como por el interés especial de algunas instituciones, como la nuestra, por estas patologías; aunque todas nuestras pacientes fueron de nuestro territorio.

Hasta 1970, estas causas de hemorragia se reportaban muy esporádicamente. Mención destacada antes de esa fecha tiene el trabajo de Cannell y Boterell en 1956 ${ }^{3}$; sin embargo, después de esa fecha ha existido un incremento notable de estos informes y la revisión que hicimos en Medline para la redacción de este trabajo evidenció 317 referencias del tema después de 1973. Muchos de esos autores opinaron que la frecuencia de esta patología aumentará con seguridad $\mathrm{d}^{21,39,40}$.

Los aneurismas saculares y las malformaciones arteriovenosas constituyen las principales causas de hemorragias subaracnoideas durante el embarazo y el puerperio. Las localizaciones de los primeros son similares a las observadas en las pacientes no obstétricas; sin embargo, existen algunos tipos poco usuales y propios de esta condición: los aneurismas disecantes postpartum de la arteria basilar y del territorio posterior ${ }^{17,44,48}$, los aneurismas relacionados con las metástasis del coriocarcinoma ${ }^{23,28}$ y los aneurismas infecciosos postaborto ${ }^{4,51}$. Nosotros no hemos observado en nuestro centro estos tres tipos de lesiones descritas durante el embarazo, lo que pudiera indicar un manejo obstétrico efectivo de las pacientes con coriocarcinoma y la eliminación de las infecciones postaborto.

En nuestro informe, al igual que en otros, los aneu- rismas constituyeron más del $75 \%$ de todas las causas de hemorragias durante el embarazo y el puerperio ${ }^{8,21}$. El embarazo se relacionó con el $88 \%$ del total y el puerperio con el $12 \%$, aunque en otras series esa primera cifra puede alcanzar hasta el $92 \%$, por una menor representación del puerperio ${ }^{26,33,37}$.

Nosotros no observamos en estos diez años, hemorragias subaracnoideas desencadenadas durante el período del parto, lo que coincide con la poca frecuencia informada por otros autores s $^{1,3,7-8,26,37}$.

No encontramos pacientes con aneurismas múltiples en esta serie. Días y Sekhar ${ }^{6}$ revisaron retrospectivamente 152 pacientes con hemorragia subaracnoidea por aneurismas intracraneales y malformaciones arteriovenosas durante el embarazo y el puerperio, extraídos de la literatura inglesa especializada y sólo añadieron dos de su propia institución. Del total de pacientes, 118 tenían aneurismas intracraneales y no hubo multiplicidad aneurismática en ninguno de esos casos. Otros estudios reportan un 7\% de multiplicidad ${ }^{26,41}$, un índice inferior al de la población general y al de nuestra propia institución ${ }^{46,47}$. Varios autores han explicado ese bajo índice de multiplicidad por la relativa juventud de las pacientes embarazadas con aneurismas intracraneales ${ }^{4,26}$.

Nosotros tampoco encontramos aneurismas grandes ni gigantes, aunque Minielly y $\operatorname{cols}^{26}$ sí comunicaron dos; pero en esa serie, donde el neurocirujano principal fue el Dr. Charles Drake, intervino el interés de ese autor por este tipo de lesiones y de las ocho pacientes informadas por ellos, cuatro fueron referidas por complejidades neuroquirúrgicas desde otros territorios.

La edad media de las pacientes con hemorragia subaracnoidea aneurismática fue superior a las determinadas por malformación arteriovenosa, muy similar a lo notificado por otros autores y al comportamiento de esas lesiones en la población general ${ }^{12,37,51}$.

La edad gestacional promedio al momento de la hemorragia fue de 31.4 semanas y no hubo diferencias significativas entre aneurismas (32.2 semanas) y malformaciones arteriovenosas (30.4 semanas). La mayor frecuencia de las hemorragias en el tercer trimestre siempre se ha relacionado con los cambios hemodinámicos del embarazo.

Aunque todos los riesgos que aportan el embarazo y el puerperio no están bien precisados en las mujeres con aneurismas y malformaciones arteriovenosas, si se conoce que están en alto peligro de ruptura y de muerte. La situación es mucho más crítica en multíparas y en los dos últimos trimestres del embarazo. Esto fue confirmado en nuestras pacientes pues todas, menos una, habían tenido partos previos.

Las mayores contradicciones radican en la asociación entre las hemorragias durante el embarazo y el puerperio y las malformaciones arteriovenosas. Existen varias series clínicas de pacientes con malformaciones arteriovenosas 
que completaron su embarazo sin complicaciones ${ }^{10,29,43}$. El estudio más significativo sobre este tópico lo hicieron Horton et $\mathrm{al}^{16}$ que realizaron un análisis retrospectivo de 451 mujeres con malformaciones arteriovenosas. De un total de 540 embarazos, 17 tuvieron hemorragias intracraneales durante ese período. Ellos calcularon que el promedio de hemorragias durante el embarazo en mujeres con malformaciones arteriovenosas no rotas fue del 3.5\% y en las no embarazadas en edad fértil con malformaciones no rotas fue de $3.1 \%$ por año. Esos investigadores concluyeron que el embarazo no fue un factor de riesgo significativo para la hemorragia en pacientes con malformaciones arteriovenosas no rotas.

Otra serie de 1992, presentada por Ondra et $\mathrm{al}^{30}$ en la Asociación Americana de Neurocirujanos, incluyó 166 pacientes fineses con malformaciones arteriovenosas. Ellos encontraron que el $14 \%$ de las hemorragias ocurrieron en el último trimestre del embarazo o durante el puerperio inmediato y concluyeron que las pacientes con malformaciones arteriovenosas, sí tienen un alto riesgo de sangrado durante el embarazo. Cuando ambos estudios son considerados juntos, es interesante señalar que no hubo hemorragias durante el trabajo de parto, la cesárea o durante el aborto.

Durante el periodo de gestación o puerperio, las malformaciones arteriovenosas sangran por su porción venosa, lo cual se correlaciona más con los cambios del volumen intravascular gestacional, que con las modificaciones de la presión arterial sistémica. Las hemorragias de las malformaciones arteriovenosas durante el embarazo son mucho más benignas que las aneurismáticas, aunque puede haber un $25 \%$ de resangrado durante el propio embarazo, una proporción superior al 3-6\% calculado en pacientes no embarazadas. Nosotros no observamos sangrados graves en las pacientes con malformaciones ni hubo fallecidas en ese grupo.

Si bien, la pregunta sobre el riesgo de la hemorragia durante el embarazo no ha tenido una respuesta concluyente, un grupo de datos sugiere con mucha fuerza que, si la hemorragia ha ocurrido durante la gestación o intraparto, el riesgo de recurrencia es elevado y en esas condiciones no debe demorarse el tratamiento agresivo microquirúrgico o endovascular de la lesión por su alta letalidad ${ }^{53}$.

Robinson et $\mathrm{al}^{36}$ identificaron tres rasgos que diferenciaron la hemorragia aneurismática de la hemorragia por malformaciones arteriovenosas durante el embarazo y el puerperio: la edad, la paridad de la madre y el tiempo de gestación cuando ocurre la hemorragia. En esa serie $\mathrm{y}$ en otras ${ }^{16,29,34,36}$ las pacientes con malformaciones arteriovenosas son más jóvenes y las pacientes con aneurismas tienen mayor paridad y una edad gestacional más avanzada, porque la hemorragia se relaciona con los cambios hemodinámicos del final del embarazo. El gasto cardíaco se incrementa en un $60 \%$ durante las primeras 28 a 32 semanas del embarazo y luego permanece constante. El volumen sanguíneo materno, la presión arterial y venosa se elevan durante la preñez y alcanzan el valor máximo al término, lo cual puede conducir a rupturas aneurismáticas $\mathrm{y}$ venosas en las malformaciones.

Mejores controles médicos durante el embarazo y sus complicaciones, una elevada sospecha clínica de la hemorragia en gestantes o puérperas con cefalea intensa y brusca y el diagnóstico temprano de las hemorragias pueden conducir por caminos más favorables y seguros a las pacientes $\mathrm{y}$ al feto.

En el pasado, Pool $^{32}$ notó que las pacientes embarazadas con hemorragias intracraneales tratadas de forma conservadora, tenían una mortalidad superior al 70\% y las operadas un $8 \%$. Esos estudios condujeron al convencimiento de la necesidad inmediata del tratamiento quirúrgico.

Antes, la tomografía computarizada y la arteriografía cerebral estaban prohibidas en las pacientes gestantes; pero ya conocemos que la primera es inocua en la embarazada en cualquier periodo gestacional si se protege adecuadamente el feto, especialmente en el primer trimestre. La arteriografía, por si misma, no implica riesgos maternofetales adicionales; además los contrastes yodados son cada vez más inertes y tienen menos riesgo para el feto. La hidratación materna debe mantenerse durante la realización de ese estudio para evitar la deshidratación del feto y se sugiere monitorizar la frecuencia cardiaca fetal por arritmias e hipotensión. Nosotros no tuvimos ninguna complicación con el uso de estos estudios, ya que aplicamos cuidados especiales y monitoreo cardiovascular en todos los casos. En todos estuvo presente el intensivista y el obstetra. En las puérperas o en las tratadas con cesárea el riesgo y la tensión de todo el equipo médico fue mucho menor.

El pronóstico de las madres y del feto estuvo bien documentado en todos nuestros casos. Una sola de las madres falleció antes del tratamiento quirúrgico por resangrado y otra después de la intervención por vasoespasmo ${ }^{45}$, lo que indica la rapidez del manejo.

La mortalidad materna por hemorragia subaracnoidea aneurismática en todos los estudios oscila entre $25-50 \%$. La prioridad que se ofrece a la atención de la embarazada complicada, la existencia de una riguroso Programa Nacional Materno Infantil, el fácil acceso a las unidades de terapia intensiva, la organización de esa atención, la experiencia de los equipos médicos en estos casos poco frecuentes, el manejo interdisciplinario y el desarrollo de la neurocirugía vascular en un centro con esta responsabilidad tienen un valor fundamental en la mejora de estos resultados.

El método microneuroquirúrgico fue utilizado en todas nuestras pacientes. No utilizamos métodos endovasculares, aunque varios autores han informado su uso con buenos resultados en pequeños grupos de pacientes ${ }^{22,31,34}$. Los trastornos hemodinámicos de la gestante y la puérpera, 
los trastornos de la coagulación sanguínea propios del embarazo, el incremento de la exposición a radiaciones y la imposibilidad de resolver algunas de estas lesiones con métodos no invasivos, nos permiten opinar que los métodos endovasculares deben considerarse con reserva en las embarazas. Muchos centros todavía continúan utilizando el método microneuroquirúrgico en los aneurismas de la arteria cerebral media, muy difíciles de resolver por métodos endovasculares ${ }^{14}$.

Siempre existió preocupación por la seguridad maternoinfantil durante los procederes quirúrgicos debido, en parte, a las experiencias pasadas en las que no se disponía de un monitoreo riguroso de la madre y el niño y no se podía detectar precozmente la hipoxia, la hipotensión, la acidosis y los trastornos hidroelectrolíticos tan dañinos para ellos ${ }^{4,41}$.

La participación integrada durante el proceder de intensivistas, anestesistas, obstetras y neurocirujanos es muy importante en el manejo de la embarazada o de la puérpera con una hemorragia intracraneal por aneurismas o malformación arteriovenosa. Existen cambios fisiológicos en el consumo de oxígeno, volumen minuto, niveles de $\mathrm{CO}_{2}$ en sangre, promedio de filtración glomerular y distribución corporal de las drogas anestésicas ${ }^{2,15,50}$.

Algunas drogas utilizadas habitualmente por la neurocirugía deben evitarse siempre que sea posible. Los diuréticos osmóticos como el manitol tiene efectos adversos sobre el feto y determina la deshidratación materna que produce hipotensión, hipoperfusión uterina y daño fetal ${ }^{2,4}$. Ese medicamento cruza la barrera maternofetal y puede acumularse en el feto y eleva su osmolaridad plasmática hasta un $50 \%$ y condiciona deshidratación, bradicardia y cianosis del feto. Nosotros no utilizamos este fármaco de manera rutinaria y sólo lo empleamos cuando su uso es imprescindible. Durante la cirugía promovemos el drenaje de líquido cisternal para evitar dosis intraoperatorias innecesarias y en el postoperatorio no lo utilizamos de rutina.

Todos los anticonvulsivantes pueden ser discutibles por su efecto deformante sobre el feto y la fenitoína, en especial, incrementa la incidencia de anomalías craneofaciales, deformidades en los miembros y retardo en el crecimiento y desarrollo mental. Nosotros evitamos el uso de ese medicamento y lo sustituimos, cuando es necesario, por la carbamacepina, con menores efectos sobre el feto. Está confirmado que la acción deletérea de las convulsiones, que determinan hipoxia y acidosis en la madre y el feto justifica el uso de drogas antiepilépticas, independientemente del riesgo $0^{4,15}$.

La nimodipina, aceptada universalmente para el tratamiento de la hemorragia subaracnoidea aneurismática, puede producir hipotensión y taquicardia tanto en la madre como en el feto. Es potencialmente teratogénico y embriotóxico, por lo que debe evaluarse si es realmente necesario.
Se le ha atribuido un efecto inhibitorio sobre la contractibilidad uterina y es antihipertensivo. Sin embargo, Hitburn ${ }^{15}$, Mayberg et $\mathrm{a}^{25}$, Bert ${ }^{2} \mathrm{y}$ nosotros la hemos utilizado sin complicaciones.

Aunque el manejo anestésico no es motivo de este trabajo, varios autores han informado su experiencia ${ }^{15,25}$; pero por lo general se trata de experiencias limitadas a muy pocos pacientes. Deben tenerse en cuenta los cambios pulmonares durante el embarazo, el incremento del 50-70\% de la ventilación alveolar, el aumento del volumen tidal hasta un $40 \%$ $y$ un incremento del $15 \%$ de la frecuencia respiratoria. Todo esto resulta en una inducción anestésica rápida, una reducción del $25-40 \%$ de los anestésicos y un incremento en el riesgo de las drogas utilizadas por inhalación. Además, puede existir un incremento de la ventilación alveolar, bajos índices arteriales de $\mathrm{PCO}_{2}$ y un $\mathrm{Ph}$ bajo, debido a la compensación metabólica. La hiperventilación utilizada para reducir la presión intracraneal no debe reducir la $\mathrm{PCO}_{2}$ por debajo de $25 \mathrm{mmHg}$. Una hiperventilación mayor es perjudicial para la madre y el niño por la vasoconstricción de las arterias umbilicales del feto. El incremento de la oxihemoglobina de la madre aumenta su afinidad por el oxígeno y se produce una menor transferencia al feto ${ }^{15,25}$.

Maybert et $\mathrm{al}^{25}$ y nosotros insistimos en la necesidad de mantener la normotensión y la normovolemia durante la anestesia. No aconsejamos tampoco la hipotensión controlada y preconizamos el clipaje transitorio del vaso aferente para provocar hipotensión localizada. La posición supina durante la cirugía en la gestante comprime la cava inferior y puede producir hipotensión por lo que puede preferirse el decúbito semilateral y controlar estrechamente los parámetros del feto y la madre como mencionamos anteriormente.

El seguimiento postoperatorio del feto y de la madre por el equipo multidisciplinario en Unidades de Terapia Intensiva es muy necesario para detectar graves complicaciones como el vasoespasmo que continúa siendo una causa principal de muerte y las trombosis venosas profundas por la compresión abdominal e inmovilidad innecesaria de estas pacientes, que deben incorporarse a la actividad física lo antes posible.

Nosotros tuvimos una fallecida por vasoespasmo postoperatorio grave y no encontramos trombosis venosas profundas en el postoperatorio de ninguna de nuestras pacientes. El uso de vendajes en miembros inferiores, una buena hidratación, la fisioterapia oportuna y la movilización precoz permiten evitar las trombosis venosas de miembros inferiores, una causa de morbilidad y potencial mortalidad de las pacientes puérperas.

La hemorragia subaracnoidea por aneurismas y malformaciones arteriovenosas es más frecuente durante el embarazo y el puerperio que en la población femenina normal y la mejoría de la atención materno-infantil en muchos 
países con Sistemas de Salud más desarrollados ha determinado una reducción de las causas de muerte obstétricas y un incremento de las causa indirectas, en especial, de las enfermedades cerebrovasculares hemorrágicas. Un mejor diagnóstico clínico, los oportunos y convincentes estudios por imágenes y la existencia de unidades de terapia intensiva para pacientes embarazadas y puérperas con manejo interdisciplinario, vinculadas a servicios con experiencia en neurocirugía vascular determinan un incremento en el diagnóstico de las hemorragias subaracnoideas por aneurismas intracraneales y malformaciones arteriovenosas que requieren un tratamiento microneuroquirúrgico o endovascular rápido y oportuno para evitar la muerte materna y el grave daño del feto.

Este tipo de pacientes requiere un manejo médico, anestésico, quirúrgico y postoperatorio especial; pero su poca frecuencia impide acumular una experiencia considerable, lo que hace necesaria la centralización y regionalización de estas pacientes en unidades de terapia intensiva que tengan vínculos estrechos con servicios obstétricos y de neurocirugía vascular.

La divulgación científica de los resultados obtenidos con esta modalidad de manejo permitirá ganar experiencia y afrontar un problema actual y creciente dentro de la atención materno-infantil y la neurocirugía vascular.

\section{Bibliografía}

1. Aminoff, M.J.: Neurological disorders and pregnancy. Am J Obstet Gynecol 1978; 132: 325-335.

2. Bert, J.A.: General anesthesia for surgical repair of intracranial aneurysms during pregnancy effect on fetal heart rate. Am J Perinat 1993, 10: 183-186.

3. Candell, D.E., Botterell, E.H.: Subarachnoid hemorrhage and pregnancy. Am J Obstet Gynecol 1956; 12: 844850 .

4. Carmel, P.W., Swift, D.M.: Sponteous intracranial hemorrhage occurring during pregnancy. En Kaufman HH (ed) Intracerebral hematomas. New York. Raven Press. 1992; pp 117-126.

5. Catanzarite, V.A., Novotny, W.F., Cousins, L.M., Schneider, J.M.: Pregnancies in a patient with congenital absense of prothrombin activity case report. Am J Perinatol 1997; 14: $135-138$

6. Días, M.S., Sekhar, L.N.: Intracraneal hemorrage from aneurysms and arteriovenous during pregnancy and the puerperium. Neurosurgery 1990; 27: 855-866.

7. Drake, C.G., Hunt, W.E., Sano, K., Kasell, N., Teasdale, G., Pertuiset, B. et al.: Report of the World Federation of Neurological Surgeons. Committee on a universal subarachnoid grading scale. J Neurosurg 1988; 68: 986-987.

8. Dumont, A.S., Kassell, N.F.: Editorial comment—-parity and risk of subarachnoid hemorrhage an emerging association.
Stroke 2004; 35: 32-33.

9. Fox, M.W.: Select Neurologic complications of pregnancy. Mayo Clin Proclmm 1990; 65: 1595-1618.

10. Fults, D., Kelly, D.L.: Natural history of arteriovenous malformations of the brain: A clinical study. Neurosurgery 1984; 15: 864-869.

11. Georgantopoulou, C., Jha, R.: Intracranial aneurysm in pregnancy presenting as hyperemesis gravidarum $\mathrm{J}$ Obstet Gynaecol 2003; 23: 74-75.

12. Giannota, S.L., Daniels, J., Golde, S.H., Zelman, V., Bayat, A.: Ruptured intracranial aneurysms during pregnancy. A report of four cases. J Reprod Med 1986; 31: 139-147.

13. Helms, A.K., Kittner, S.J.: Pregnancy and stroke. CNS Spectr 2005; 10: 580-587.

14. Heros, R.C., Fritsch, M.J.: Surgical Management of middle cerebral artery aneurysms. Neurosurgery 2001; 48: 780-786.

15. Hitburn, R.H., Laishley, R.S., Jewkes, D.A.: Anaesthesia for simultaneous cesarean section and clipping of intracerebral aneurysm. Br J Anaesth 1990; 64: 642-645.

16. Horton, J.C., Chambers, W.A., Lyons, S. at al.: Pregnancy and the risk of hemorraghage from cerebral arteriovenous malformations. Neurosurgery 1990; 27: 867-873.

17. Ikeda, K., Shoin, K., Taguchi, H., Yamano, J., Kawahara, R.: Postpartum dissecting aneurysms of the superior cerebellar artery—case report. Neurol Med Chir 1999; 39: 852-457.

18. Jennett, B., Bord, M.R.: Assesment of outcome after severe brain damages. A practical scale. Lancet 1975; 1: 480484.

19. Kassell, N.F., Torner, J.C., Haley, C., Jane, J.A., Adams, H.P., Kongable, GL.: The International Cooperative Study on the timing of Aneurysms Surgery. Part 1: Overall management results. J Neurosurg 1990; 73: 18-36.

20. Kassell, N.F., Torner, J.C., Jane, J.A., Haley, E.C., Adams, H.P.: The International Cooperative study on the timing of aneurysms surgery Part 2: Surgical results. J Neurosurg 1990; 73: 37- 47.

21. Kittner, S.J., Stern, B.J., Feeser, B.R. et al.: Pregnancy and the risk of stroke. N Engl J Med 1996; 335: 768-774.

22. Kizilkilic, O., Albayram, S., Adaletli, I., et al.: Endovascular treatment of ruptured intracranial aneurysms during pregnancy: report of three cases. Arch Gynecol Obstet 2003; 268: 325-328.

23. Komeichi, T., Igarashi, K., Takigami, M., et al.: A case of metastatic choriocarcinoma associated with cerebral trombosis and aneurysmal formation. No Shinkei Geka 1996; 24 : 463-467.

24. Lanzino, G., Wakloo, A.K., Fessler, R.D., Hartney, M.L., Guterman, L.R., Hopkins, L.N.: Efficacy and current limitations of intravascular stents for intracranial internal carotid, vertebral and basilar artery aneurysms. J Neurosurg 1999; 91: 538-546. 
25. Mayberg, M.R., Batjer, H.H., Dacey, R.: Guidelines for the management of aneurysmal subarachnoid hemorrhage. Circulation 1994, 90: 2592-2605.

26. Minielly, R., Yuzpe, A.A., Drake, C.G.: Subarachnoid hemorrhage secondary to ruptured cerebral aneurysm in pregnancy. Obstetrics and Gynecology 1979; 53: 64-70.

27. Momma, F., Beck, H., Miyamoto, T., Nagao, S.: Subarachnoid hemorrhage secondary to ruptured cerebral aneurysm in pregnancy. Obstet Gynecol 1979; 53: 64-70.

28. Momma, F., Beck, H., Miyamoto, T., Nagao, S.: Intracranial aneurysm due to metastatic choriocarcinoma. Surg Neurol 1986; 25: 74-76.

29. Newton, C.L., Bell, S.D.: Arteriovenous malformation in the pregnant patient: a case study. J Neurosci Nurs 1995, 27 : 109-112.

30. Ondra, S.L., Troup, H., George, E.D., et al.: The natural history of symptomatic arteriovenous malformations of the brain: A 24 year follow-up assessment. J Neurosurg 1990; 73 : 387-392.

31. Piotin, M., de Souza Filho, C.B., Kothimbakam, R., Moret, J.: Endovascular treatment of acutely ruptured intracranial aneurysms in pregnancy. Am J Obstet Gynecol 2001; 185: 1261-1262.

32. Pool, J.L.: Treatment of intracranial aneurysms during pregnancy. JAMA 1963; 192: 209-214.

33. Powell, S., Rijhsinghani, A.: Ruptured bacterial intracranial aneurysms in pregnancy. A case report. J Reprod Med 1997: 42: 455-458.

34. Qureshi, A.J., Giles, W.H., Croft, J.B., et al.: Number of pregnancy and risk for stroke and stroke subtypes. Arch Neurol 1997, 54: 203-206.

35. Riviello, C., Ammannati, F., Bordi, L., et al.: Pregnancy and subarachnoid hemorrhage: a review. J Matern Fetal Neonatal Med 2004; 16: 245-246.

36. Robinson, J.L., Hall, C.S., Sedzimir, C.B.: Arteriovenous malformations, aneurysms and pregnancy. J Neurosurg 1974; 41: 63-70.

37. Roman, H., Descargues, G., Lopes, M., et al.: Subarachnoid hemorrhage due to cerebral aneurysmal rupture during pregnancy. Acta Obstet Gynecol Scand 2004; 83: 330-334.

38. Rossi, A., Cella, R., Balestrero, M.A., Garlasco, M.G., Caramella, F., Siani, C.: Subarachnoid hemorrhage and pregnancy. Minerva Anestesiol 1998; 64: 189-191.

39. Sadasivan, B., Malik, G.M., Lee, C., Ausman, J.I.: Vascular malformations and pregnancy. Surg Neurol 1990; 33: 305-313.

40. Selo-Ojeme, D.O., Marshman, L.A., Ikomi, A., et al.:
Aneurysmal subarachnoid haemorrhage in pregnancy. Eur J Obstet Gynecol Reprod Biol 2004; 116: 131-143.

41. Singer, J.R., Hummelgard, A.B., Martin, E.M.: Ruptured aneurysms in pregnancy. J Neurosurg Nurs 1985, 17: 230-237.

42. Spetzler, R.F., Martin, N.A.: A proposal grading system for arteriovenous malformations of the brainstem. J Neurosurgery 1986; 65: 476-480.

43. Stoodley, M.A., Macdonald, R.L., Weir, B.K.: Pregnancy and intracranial aneurysms. Neurosurg Clin N Am 1998; 9: 549-556.

44. Van de Kelt, E., Kunnen, J., Truyen, L., et al.: Postpartum dissecting aneurysms of the basilar aneurysms Stroke 1992; 23. 114-119.

45. Varela Hernández, A., Vega Basulto, S.D., Herrera Lorenzo, O., de Zayas Alba, E., Infante Ferrer, J.: Vasoespasmo cerebral. Un reto de la medicina moderna. Rev Mex Neurosci 2005; 6: 491-499.

46. Vega Basulto, S.D., Silva Adán, S., Peñones Montero, R.: Aneurismas intracraneales múltiples en Camagüey (Cuba). Rev Neurol 2003; 37: 112-117.

47. Vega Basulto, S.D., Silva Adán, S., Peñones Montero, R.: Tratamiento de los aneurismas intracraneales múltiples. Neurocirugía 2003, 14: 385-391.

48. Vega Basulto, S.D., Rivero García, C., Gutiérrez Muñoz, F.: Aneurismas cerebrales disecantes. Rev Neurol 2004; 38: 1142-1148.

49. Vega Basulto, S.D.: La entrevista con los familiares del paciente neuroquirúrgico. Neurocirugía 2004; 14: 391-399.

50. Wilson, S.R., Hirsch, N.P., Appleby, I.: Management of subarachnoid haemorrhage in a non-neurosurgical centerAnaesthesia 2005; 60: 470-485.

51. Weir, B., Findlay, J.M.: Subarachnoid hemorrhage. En Carter LP, Spetzler RF (ed) Neurovascular Surgery. New York. McGraw-Hill 1995; pp 557- 582.

52. Wiebers, D.O.: Subarachnoid hemorrage in pregnancy. Semin Neurol 1988; 8: 226-229.

53. Yasargil, M.G.: Microneurosurgery III B. Stuttgart. Georg Thieme Verlag 1988.

Vega-Basulto, S.D.; Lafontaine-Terry, E.; GutiérrezMuñoz, F.G.; Roura-Carrasco, J.; Pardo-Camacho, G.: Hemorragia intracraneal por aneurismas y malformaciones arteriovenosas durante el embarazo y el puerperio. Neurocirugía 2008; 19: 25-34.

Correspondencia postal: Domingo Puentes 5. Entre San Joaquín y Carretera central. La Caridad. Camagüey 70300. Cuba. 
Comentario al trabajo: "Hemorragia intracraneal por aneurismas y malformaciones arteriovenosas durante el embarazo y el puerperio" de Vega Basulto y cols.

Por su relativa rareza siempre nos sorprende cuando una paciente embarazada sufre una hemorragia cerebral parenquimatosa o subaracnoidea (HSA) secundaria a una malformación arteriovenosa ó a un aneurisma. Muchas veces, se producen inflamadas discusiones sobre aspectos éticos o bioéticos de cómo tratar a estos pacientes; la madre y el feto.

Los hospitales tienen protocolos para el tratamiento de la HSA y de la hemorragia cerebral (no tantas veces), pero para estos casos concretos no hay protocolos. Por otra parte, me permito recordar que la última vez que nos reunimos para hablar de qué hacer con una paciente embarazada afecta de una HSA por aneurisma de la comunicante anterior diagnosticado por angioRM, en la sala donde discutíamos neurólogos, intensivistas, obstetras y nosotros, neurocirujanos, colgaba de la pared un cuadro con el siguiente texto: Protocolos: conjunto de normas generales que al médico competente le sirven de orientación y que el que no lo es tanto los sigue al pie de la letra. Nosotros ofrecimos operarla aquella noche, pero el resto del equipo multidisciplinario declinó nuestra oferta y prefirió que al día siguiente, de día, se tratara por vía endovascular. La evolución tanto de la madre como del feto fue satisfactoria. En los últimos años hemos tratado quirúrgicamente de MAV a tres pacientes durante el embarazo que evolucionaron bien así como los fetos y cuatro pacientes con HSA aneurismática falleciendo una madre y dos fetos, el resto tuvieron un curso clínico favorable.

Estamos de acuerdo con las recomendaciones de Vega Basulto que se pueden extraer de su trabajo y podemos resumir que a las pacientes embarazadas las debemos tratar igual como las trataríamos si no estuvieran embarazadas, pero teniendo en cuenta que están embarazadas, en otras palabras, escoger, cuando es posible, los tratamientos, posturas quirúrgicas, etc. más inofensivas para el feto. La urgencia de tratar un aneurisma que ha sangrado nadie la discute, es discutible tratar con premura una MAV que ha sangrado; no obstante, el riesgo de resangrar no es despreciable y por tanto, nuestra actitud debe ser la misma que tomaríamos con una paciente que no estuviera embarazada y el tratamiento quirúrgico sigue siendo el más efectivo.

J. Vilalta

Barcelona 